\title{
Phytochemical, Chemical and Biomedical Characterization of Crude Extracts of Macrosphyra longistyla (DC.) Hiern
}

\author{
Ernest U. Durugbo 1,*, James O. Ogah ${ }^{2}$, Nwankwo Chukwuemeka ${ }^{1}$, \\ Peter G. Sename ${ }^{1}$, Adedayo T. Olukanni ${ }^{3,4}$, Kafayat O. Yusuf ${ }^{2}$, \\ Isioma C. Awuzie ${ }^{2}$ Olumide D. Olukanni ${ }^{3}$, and Simbo O. Aboaba ${ }^{2}$ \\ ${ }^{1}$ Department of Biological Sciences, Redeemer's University, P.M.B. 230, Ede, Osun State, Nigeria. ${ }^{2}$ Department of Microbiology, University \\ of Lagos, Akoka-Yaba, Lagos, Nigeria; ${ }^{3}$ Department of Biochemistry, Redeemer's University, P.M.B. 230, Ede, Osun State, \\ Nigeria; ${ }^{4}$ Department of Cell Biology and Genetics, University of Lagos, Akoka-Yaba, Lagos, Nigeria.
}

Received: April 17, 2020; Revised: August 30, 2020; Accepted: September 15, 2020

\begin{abstract}
Phytochemical analysis of Macrosphyra longistyla leaf, stem bark, and root extracts revealed different constituents. The GCMS analyses of their ethanolic extracts showed the presence of bioactive compounds: the stem bark yielded 9 compounds, such as squalene, vitamin E, and fatty acids; the root extract revealed 10 different compounds, especially morpholine, isophorone and fatty acids. The extracts demonstrated high proteinase inhibition potentials. The aqueous, ethanol and ethyl acetate extracts of the leaf, stem bark, and root were tested against Methicillin-Resistant Staphylococcus aureus (MRSA) 144m, Escherichia coli ATCC11229, Salmonella typhimurium ATCC13311, Enterococcus faeciumATCC700221, Shigella flexneri ATCC12012 and laboratory strain of Streptococcus mutans with the diameter of zone of inhibitions ranging from 10 to $40 \mathrm{~mm}$. The study revealed a marked susceptibility pattern of the test organisms to the ethanol and ethyl-acetate extracts showing varied diameter of zones of inhibitions. The aqueous extract was ineffective against the pathogens.. The minimum inhibitory concentrations (MIC) ranged from $25-100 \mathrm{mg} / \mathrm{ml}$. All the test organisms except $S$. mutans were susceptible to

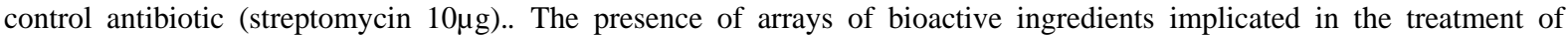
specific ailments has provided a scientific justification for Macrophyla longistyla as an alternative remedy for the treatment of bacterial infections.
\end{abstract}

Keywords: Macrosphyra longistyla, DPPH scavenging, isophorone, plants alkyne, antibacterial agents.

\section{Introduction}

Numerous medicinal herbal plants have been associated with the treatment and the prevention of different diseases for thousands of years (Wang et al. 2012). This association, however, diminished with the discovery of antibiotics. As resistant pathogens develop and spread, the effectiveness of the antibiotics also diminished. In recent years, clinically relevant bacteria with multiple drug-resistant (MDR) strains had been reported globally (Andersson and Levin, 1999; Davies and Davies, 2010; Odumosu et al. 2017).

Bouyahaya et al. (2017) reported that numerous research works had demonstrated the potential of medicinal plants used in different traditional, complementary, and alternative disease treatments. Jaiswal and Sharma (2020) further added that in the last two decades, different parts of the plant such as leaves, stem, seeds, flowers, fruits, and roots of many medicinal plants and weeds had been documented to exert antibacterial potentials. They together with (Belakhdar et al. 2015; Maffo et al. 2015; Al-Jadidi and Hossain, 2016; Bouyahya et al, 2016; Lopez-Rubalava and Estrada-Camarena, 2016; Karthikeyan et al. 2009; Saranraj and Sivasakthi, 2014) had attributed this ability to various secondary metabolites such as tannins, terpenoids, alkaloids, flavonoids, phenols, glycosides, saponins, fatty acids, gums, resins, and steroids, present in these medicinal plants. Recently, interest in plant extracts exhibiting antimicrobials and pharmacological applications has been increasing (; Sacan 2018; Singh and Sharma, 2019; Jaiswal and Sharma, 2020; Mak et al. 2013; Yigit, 2018).

Macrosphyra longistyla (DC.) Hiern is a popular medicinal plant in West Africa (Burkill, 1995; Govaerts et al. 2003; Arbonnier, 2000). It belongs to the family Rubiaceae. The plant parts used include the fruit, leaf, and also flower. Generally, the flower is used for healing; the young leaves are boiled and eaten as vegetables. The leaves are excellent treatments for cutaneous, subcutaneous parasitic infections, abortifacients, embolic, and leprosy. The roots are diuretic and useful for treating kidney problems (Arbonnier, 2000).

Since the main antimalarial drug quinine is of Rubiaceae origin, researchers tend to infer that similar compounds with similar properties may occur in other genera of the family Rubiaceae (Karou et al. 2011). Singh and Sharma (2019) had reviewed the therapeutic potentials of plant-based natural compounds used for malaria treatment. From the available literature, reports on $M$.

\footnotetext{
*Corresponding author e-mail: durugboe@run.edu.ng.
} 
longistyla are scarce (Odugbemi, 2008; Elufioye et al. 2019). Hence, this study was set out to investigate the phytochemical components and antibacterial activities of ethanolic, aqueous and ethyl acetate of the leaf, stem bark, and root extracts of $M$. longistyla on selected bacteria.

\section{Material and Methods}

\subsection{Collection of plant materials}

The fresh stem-bark, leaves, and roots of Macrosphyra longistyla were collected from within the premises of Redeemer's University Ede, Osun State, Nigeria, in March 2018. The plant specimen was identified by Dr. Ernest Durugbo of the Department of Biological Sciences Redeemer's University and later authenticated by Dr. George Nodza at the University of Lagos Herbarium and a voucher number LUH 8194 assigned. The plant materials were air-dried for two weeks at room temperature crushed and grounded into powder, using mortar and pestle ready for extraction.

\subsection{Preparation of crude extracts}

The extraction of powdered plant material was carried out by maceration, as previously described (Ogah and Osundare, 2015). Thirty grams (30 g) of dry powdered materials percolated in $300 \mathrm{ml}$ of absolute ethanol, ethylacetate, and distilled water in $500 \mathrm{ml}$ conical flasks were stoppered and kept for 48 hours at room temperature $\left(28 \pm 2^{\circ} \mathrm{C}\right)$. The extracts were filtered with Whatman No. 1 filter paper, concentrated at $40^{\circ} \mathrm{C}$ using a rotary evaporator (REL200, Bibby Sterlin, England, Agyare et al. 2014), and the concentrated extracts were used for the antibacterial assay and further analysis.

\subsection{Selection of Bacteria culture}

The pure typed bacteria cultures of MethicillinResistant Staphylococcus aureus (MRSA)144m, Escherichia coli ATCC11229, Salmonella typhimurium ATCC13311, Enterococcus faecium ATCC700221, Shigella flexneri ATCC12012 and Laboratory strain of Streptococcus mutans used for the antibacterial assay were obtained from the pure culture laboratory of Microbiology Department of the University of Lagos, Akoka-Yaba, Lagos, Nigeria. They were maintained in glycerol-peptone water at $4^{\circ} \mathrm{C}$ before use.

\subsection{Antibacterial Study}

The bacterial cultures were inoculated in MuellerHinton Broth to obtain a fresh 18-h old culture for the assay. The leaf, stem bark and root extracts of $M$. longistyla were tested using the well-diffusion method described by CLSI. A stock solution of extract consists of $0.4 \mathrm{~g}$ of plant material in $1 \mathrm{ml}$ of water. A loopful of bacterial colonies from overnight culture was inoculated into sterile Mueller-Hinton Broth (MHB). Broth inoculums were incubated at $37^{\circ} \mathrm{C}$ for $16-20 \mathrm{~h}$. Broth inoculums were standardized to 0.5 McFarland standards using dilution with sterile MHB and measuring the optical density $t$ at $625 \mathrm{~nm}$ wavelengths. Absorbance readings were fixed within the range of $0.08-0.13$ (equivalent to approximately $1.5 \times 10^{8} \mathrm{CFU} / \mathrm{mL}$ ). Standardized broth inoculums were lawned onto sterile Muller Hinton Agar by swabbing with sterile cotton swabs and allowed to sit for 10 minutes. Wells (6 $\mathrm{mm}$ in diameter) were bored into the solidified and well-seeded agar equidistant to each other with a cork borer. Streptomycin, a standard antibiotic, was used as the positive control for the test organisms, while $1 \%$ DMSO was the negative control. Each plant extract $(100 \mu l)$ was dispensed into the wells in triplicates. The agar plates were kept at room temperature for $10 \mathrm{~min}$ before incubation at $37^{\circ} \mathrm{C}$ for $18-24 \mathrm{~h}$. The diameter zones of inhibition were measured using a ruler in millimeters, and the average zone was taken.

\subsubsection{Minimum Inhibitory Concentration of M. longistyla} on the selected Bacterial Isolates

The minimum inhibitory concentrations (MIC) of the extracts of $M$. longistyla were determined by the double dilution technique (Ochei and Kolhatkar, 2004). Known weights of plant extracts were diluted with physiological saline $(0.85 \%)$ into four different concentrations $(100,50$, 25 and $12.5 \mathrm{mg} / \mathrm{ml})$. One hundred microliters $(100 \mu \mathrm{l})$ of different dilutions were inoculated (Cheesbrough, 2013), and incubated at $37^{\circ} \mathrm{C}$ for $24 \mathrm{~h}$. After the overnight incubation, the lowest concentrations of the extract that inhibited the organisms' growth were taken as the minimum inhibitory concentration.

\subsection{Qualitative phytochemical analysis}

Ethanol extracts of the various parts of $M$. longistyla were screened for the presence of bioactive chemicals such as alkaloids using Mayer's reagents, flavonoids with sodium hydroxide test as described by Trease and Evans (2002). Tannins and saponins were detected using ferric salt and frothing tests, respectively, according to the standard procedures described by Parekh and Chanda (2007) while Steroids, terpenoids, and phlobatannins were screened as documented by Harborne (1998).

\subsection{Quantitative phytochemicals analysis}

\subsubsection{Determination of total phenolic content}

The total phenolic compounds in the various extracts of the plant were determined with Folin-Ciocalteu reagent using the method of Ebrahimzadeh et al. (2008). To 0.5 $\mathrm{mL}$ of each sample (in triplicates) of plant extract in methanol solution $(1 \mathrm{mg} / \mathrm{mL}), 2.5 \mathrm{~mL}$ of $10 \%$ FolinCiocalteu reagent and $2 \mathrm{~mL}$ of $\mathrm{Na}_{2} \mathrm{CO}_{3}(2 \% \mathrm{w} / \mathrm{v})$ was added. The mixture was incubated at $50^{\circ} \mathrm{C}$ for $30 \mathrm{~min}$, and the absorbance was measured at $765 \mathrm{~nm}$ using a U.V./visible spectrophotometer. Concentrations of the phenolic compounds in the extracts were extrapolated from a calibration curve of Gallic acid. Results were expressed as mg Gallic acid equivalent/g of extract.

\subsubsection{Determination of total flavonoids content}

Total flavonoids content was determined using the colorimetric method of Singleton and Rossi (1965) to extract and estimate flavonoids with some modifications. Flavonoids react with vanillin to produce a colored product, which can be measured spectrophotometrically. According to the procedure, $250 \mu \mathrm{l}$ of the extract was added to $1.25 \mathrm{ml}$ of distilled water and $75 \mu \mathrm{l}$ of $5 \%$ $\mathrm{NaNO}_{2}$. After $5 \mathrm{~min}, 150 \mu \mathrm{l}$ of $10 \% \mathrm{AlCl}_{3} \cdot \mathrm{H}_{2} \mathrm{O}$ was added, followed by $500 \mu \mathrm{l}$ of $1 \mathrm{M} \mathrm{NaOH}$ and $275 \mu \mathrm{l}$ of distilled water after $6 \mathrm{~min}$. The solution was adequately mixed, and the color intensity of the mixture read at 510 $\mathrm{nm}$. The standard used was Gallic acid. 


\subsubsection{Estimation of antioxidant activity}

The antioxidant activity was measured using the DPPH assay. This spectrophotometric assay uses the stable radical 1, 1-diphenyl-1- picrylhydrazyl (DPPH) as a reagent (Amarowicz et al. 2004). The DPPH free radical is commercially available, and it was prepared at a $0.1 \mathrm{mM}$ concentration (25 mg/L) in methanol (Sánchez-Moreno et al. 1998; Larrauri et al. 1999; Sasidharan et al. 2011). The absorbance at $518 \mathrm{~nm}$ was monitored in the presence of different concentrations of extracts. The blank experiment was carried out to determine the absorbance of DPPH before interacting.

\subsubsection{Proteinase inhibition assay}

The method of Kunitz (1947) was used for the proteinase inhibition study. One $\mathrm{mL}$ aliquot of trypsin [EC 3.4.21.4, SRL, India (1000 units/mg)] (0.5 mg/mL prepared in $0.1 \mathrm{M}$ phosphate buffer $\mathrm{pH}$ 7) was preincubated with $1 \mathrm{~mL}$ of varied concentration of the plant extracts and aspirin (standard) at $37^{\circ} \mathrm{C}$ for $15 \mathrm{~min}$. To the mixture, $2 \mathrm{~mL}$ of $1 \%$ casein (S.R.L., India) (prepared in $0.1 \mathrm{M}$ phosphate buffer) was added and incubated at $37^{\circ} \mathrm{C}$ for $30 \mathrm{~min}$. The reaction was terminated with $2.5 \mathrm{~mL}$ of $0.44 \mathrm{M}$ trichloroacetic acid (TCA) solution. The reaction mixture was centrifuged to remove the precipitated protein at 10,000 rpm for $15 \mathrm{~min}$ (Eppendorf, Germany). The absorbance of the clear supernatant was measured at $280 \mathrm{~nm}$ in a UV-Visible spectrophotometer (Shimadzu, Japan) against appropriate blanks. The formula below gave percentage inhibition:

$$
\% \text { Inhibition }=\frac{\text { Absorbance of control }- \text { Absorbance of test }}{\text { Absorbance of control }} \times 100 \%
$$

\subsection{GC-MS Analysis}

Gas Chromatography-Mass Spectrometry (GC-MS) Analysis of Crude Extracts of $M$. longistyla

GC-MS analysis was carried out on the extracts according to the protocol previously described by Odumosu et al. (2017) using a 7890A Gas Chromatography system (Agilent Technology HP5MS), with a mass spectrometer (5975C VLMSD) as a detector. The column has a length of $30 \mathrm{~m}$, the internal diameter of $0.32 \mathrm{~mm}$, and thickness of $0.25 \mu \mathrm{m}$; volume injected was 1 $\mu \mathrm{L}$, and the injector temperature was $250^{\circ} \mathrm{C}$, Helium was the carrier gas, and oven temperature initially programmed at $80^{\circ} \mathrm{C}$ for $2 \mathrm{~min}$, increased at $10^{\circ} \mathrm{C}$ per min to $240^{\circ} \mathrm{C}$, and held for 6 min. Interpretation of the mass spectrum of GCMS was conducted using the National Institute Standard and Technology (NIST) database. Unknown spectra were compared with those of the known ones stored in the NIST library.

\section{Results and Discussions}

Qualitative phytochemical screening of the ethanolic extract of $M$. longistyla revealed that the leaf extract contained almost all the tested phytochemicals except alkaloids. The stem bark had only alkaloids, flavonoids, saponins, steroids, and tannins. In contrast, the root contained flavonoids, saponins, steroids, and carbohydrates (Table 1). Some of these compounds are known to possess antimicrobial activities.
Table 1. Phytochemical content of ethanolic extracts of Macrosphyra longistyla

\begin{tabular}{llll}
\hline Group & \multicolumn{2}{l}{ Plant parts } \\
\cline { 2 - 4 } & Stem bark & Leaf & Root \\
\hline Alkaloids & + & - & - \\
Flavonoids & + & + & + \\
Saponins & + & + & + \\
Steroids & + & + & + \\
Tannins & + & + & - \\
Terpenoids & - & + & - \\
Phobatannin & - & + & - \\
Carbohydrate & - & + & + \\
Amino acids and & - & + & - \\
proteins & & &
\end{tabular}

The quantitative phytochemical contents (total polyphenols and total flavonoids) of the various parts of Macrosphyra longistyla are shown in Table 2. The leaves presented the highest content of total polyphenols (226.69 $\pm 4.53 \mathrm{mg} / \mathrm{g}$ gallic acid equivalents (GAE). Although the root extract has the lowest content of total polyphenols, it demonstrated high flavonoid content $(254.25 \pm 4.75)$.

Table 2. Total phenols, total flavonoids and DPPH scavenging activities of extracts

\begin{tabular}{llll}
\hline $\begin{array}{l}\text { Plant } \\
\text { extract }\end{array}$ & $\begin{array}{l}\text { Total polyphenols } \\
\text { (G.A.E./g extract) }\end{array}$ & $\begin{array}{l}\text { Total flavonoids } \\
\text { (G.A.E./g extract) }\end{array}$ & $\begin{array}{l}\text { DPPH Assay } \\
\text { (IC50 }(\mu \mathrm{g} / \mathrm{mL})\end{array}$ \\
\hline GA. $\square$ & - & - & $16.78 \pm 1.14^{\mathrm{a}}$ \\
MLS & $226.60 \pm 4.53$ & $180.29 \pm 5.61$ & $43.33 \pm 1.83^{\mathrm{b}}$ \\
MLL & $271.27 \pm 19.88$ & $287.10 \pm 5.83$ & $73.07 \pm 2.86^{\mathrm{c}}$ \\
MLR & $115.13 \pm 13.74$ & $254.25 \pm 4.75$ & $114.87 \pm 3.13^{\mathrm{d}}$ \\
\hline
\end{tabular}

The DPPH assay is a spectrophotometric measurement of the color changes, from violet to yellow, when an antioxidant substance scavenges the radical, reducing it to hydrazine. The ML leaf extract showed relatively high antioxidant capacity with an IC50 of $43.33 \pm 1.83 \mu \mathrm{g} / \mathrm{mL}$ while the standard had an IC50 of $16.78 \pm 1.14 \mu \mathrm{g} / \mathrm{mL}$ (Figure 1 and Table 2). The ML root and stem fractions showed high IC50 values comparable to those of plants with low antioxidant activities. These results agreed with the content of polyphenols found in the fractions (MLL> MLR> MLS) and were significantly different from those of the total flavonoids; thus, it is impeccable to attribute the antioxidant capacity of the various ML parts to the polyphenol and/or flavonoid contents. This relationship has been described by many authors using various plants species (Schubert et al. 2007; Zadra et al. 2012) (Fig. 1). 


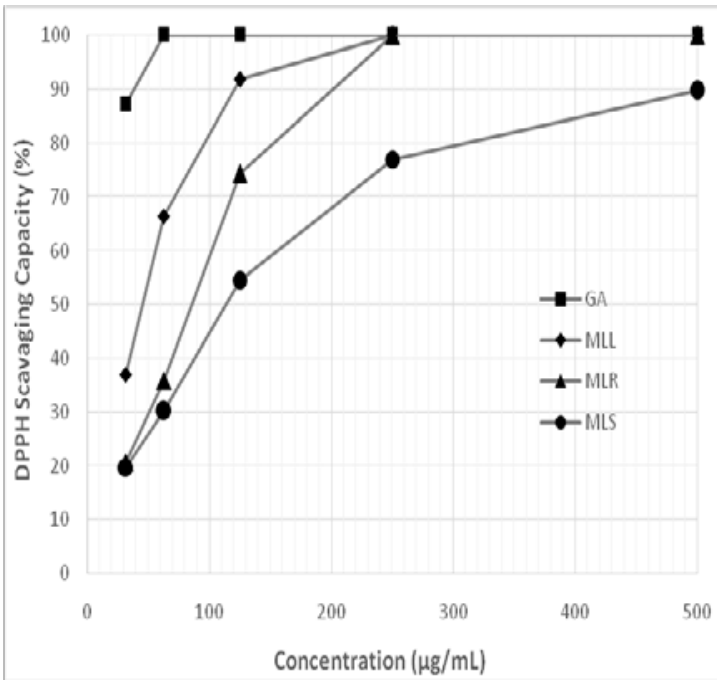

Figure 1. Antioxidant capacity of methanol extracts of various parts of M. longistyla using DPPH assay $(n=3)$

Figure 2 shows the reducing power potentials of the ethanol extracts of ML compared to the gallic acid standard at $700 \mathrm{~nm}$. The reducing capacity of the extracts, a significant indicator of antioxidant activity, was found to be appreciable. The results showed that there were increases in the reductive capability of the extracts from ML. The leaf (MLL), and stem extracts (MLS) showed a comparable high reducing ability of 1.49 and 1.46 at 0.2 $\mathrm{mg} / \mathrm{mL}$ when compared with the ascorbate control (1.67). This reducing activity is higher than that reported by Atolani et al. (2011), who worked on Kigelia pinnata, even at a high concentration of $0.4 \mathrm{mg} / \mathrm{mL}$. However, the findings are in tandem with recent works of Kudumula et al. (2018), who did an extensive survey on selected medicinal plants used in the treatment of bacterial infections in South Africa (Fig. 2).

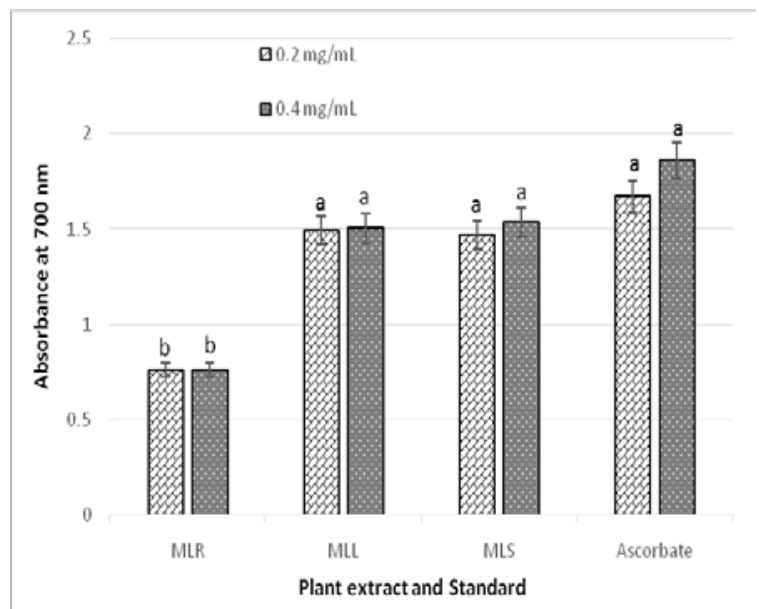

Figure 2. The reducing power potential of the selected plant extracts and ascorbic acid, with absorbance increasing with increasing concentration (values with different alphabets are significantly different at $\mathrm{p}=0.05$, t-test).
Similarly, the extracts demonstrated high proteinase inhibition potential competing effectively with the Aspirin standard, as shown by their inhibition effect on trypsin (Figure 3). Trypsin inhibitors are serine based inhibitors and are of high pharmaceutical importance (Bejina et al. 2011). Proteinase inhibitors are generally good antiinflammatory drugs, suggesting that ML will be a good candidate for drug development and direct consumption for locals as a pain-killer.

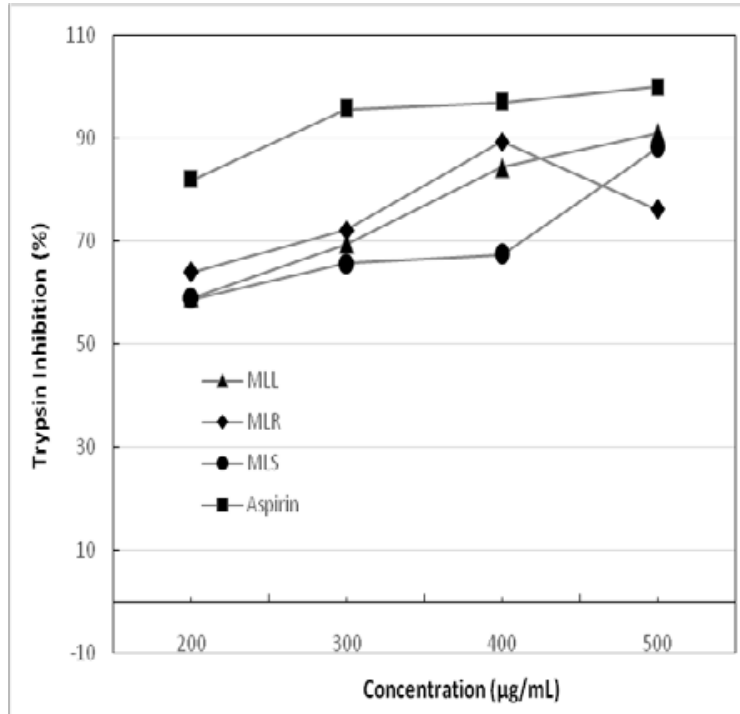

Figure 3. Trypsin inhibitory activities of extracts from various parts of Macrosphyra longistyla

The antibacterial activities of the crude extracts of stem-bark, leaves, and roots of $M$. longistyla showed zones of inhibition in millimetres against the clinical isolates ranging from 10 to $40 \mathrm{~mm}$ (Table 3) with minimum inhibitory concentration (MIC) ranging from $25-100$ $\mathrm{mg} / \mathrm{ml}$ (Table 4). GC- MS analyses showed a significant presence of bioactive compounds from ethanolic crude extracts and their characteristics (Tables 5 and 6). The chromatograms of the ethanolic extracts of the root and stem are shown in Figures 4 and 5, respectively. 
Table 3. Antibacterial Activity of Extracts of Macrosphyra longistyla against Bacterial Isolates

\begin{tabular}{|c|c|c|c|c|c|c|c|c|c|c|}
\hline \multirow[t]{2}{*}{ Bacterial Isolates } & \multicolumn{10}{|c|}{ The diameter of the zone of inhibition in millimeter (mm) $\square \square$} \\
\hline & A & $\mathrm{B}$ & $\mathrm{C}$ & $\mathrm{D}$ & $\mathrm{E}$ & $\mathrm{F}$ & G & $\mathrm{H}$ & I & $\mathrm{J}$ \\
\hline MRSA (144m) & - & - & - & 40 & 35 & 26 & - & 14 & 23 & 27 \\
\hline E. coli ATCC11229 & - & - & - & 27 & 23 & 33 & 22 & 15 & 24 & 11 \\
\hline S. typhimurium ATCC13311 & - & - & - & - & 39 & - & 32 & 31 & - & 15 \\
\hline E. faecium ATCC700221 & - & - & - & 24 & 36 & - & 19 & 26 & 20 & 12 \\
\hline S. flexneri ATCC12012 & - & - & - & 12 & 39 & - & - & 17 & - & 10 \\
\hline S. mutans & - & - & - & 19 & 32 & 18 & - & 19 & 15 & - \\
\hline
\end{tabular}

Zone of inhibition included 8mm cork-borer, - resistance, $\mathbf{A}=$ Aqueous stem extract, $\mathbf{B}=$ Aqueous leaf extract, $\mathbf{C}=$ Aqueous root extract, $\mathbf{D}=$ Ethanol stem extract, $\mathbf{E}=$ Ethanol leaf extract, $\mathbf{F}=$ Ethanol root extract, $\mathbf{G}=$ Ethyl-acetate stem extract, $\mathbf{H}=$ Ethyl-acetate leaf extract, $\mathbf{I}=$ Ethyl-acetate root extract, $\mathbf{J}=$ Streptomycin $(10 \mu \mathrm{g})$.

Table 4. Minimum Inhibitory Concentration of Extracts of Macrosphyra longistyla against Bacterial Isolates

\begin{tabular}{|c|c|c|c|c|c|c|c|c|c|}
\hline \multirow[t]{2}{*}{ Bacterial Isolates } & \multicolumn{9}{|c|}{ Minimum inhibitory concentration (MIC) in mg/ml $\square \square$} \\
\hline & A & $\mathrm{B}$ & $\mathrm{C}$ & $\mathrm{D}$ & $\mathrm{E}$ & $\mathrm{F}$ & G & $\mathrm{H}$ & I \\
\hline $\operatorname{MRSA}(144 m)$ & - & - & - & 25 & 25 & 50 & - & 50 & 50 \\
\hline E. coli ATCC11229 & - & - & - & 25 & 100 & 50 & 25 & 25 & 25 \\
\hline S. typhimurium ATCC13311 & - & - & - & - & 50 & - & 25 & 50 & - \\
\hline E. faecium ATCC700221 & - & - & - & 100 & 50 & - & 50 & 25 & 100 \\
\hline S. flexneri ATCC12012 & - & - & - & 100 & 50 & - & - & 100 & - \\
\hline S. mutans & - & - & - & 25 & 25 & 50 & - & 100 & 100 \\
\hline
\end{tabular}

Zone of inhibition included 8mm cork-borer, - resistance, $\mathbf{A}=$ Aqueous stem extract, $\mathbf{B}=$ Aqueous leaf extract, $\mathbf{C}=$ Aqueous root extract, $\mathbf{D}=$ =thanol stem extract, $\mathbf{E}=$ Ethanol leaf extract, $\mathbf{F}=$ Ethanol root extract, $\mathbf{G}=$ Ethyl-acetate stem extract, $\mathbf{H}=$ Ethyl-acetate leaf extract, $\mathbf{I}=$ Ethyl-acetate root extract, $\mathbf{J}=$ Streptomycin $(10 \mu \mathrm{g})$.

The ability of the stem, leaf and root extracts of $M$. longistyla in this study to inhibit both Gram-positive and Gram-negative bacteria is an indication of its broadspectrum activity; hence, a potential source of drugs for the treatment of dental caries, diarrhoea, skin and wound infections, typhoid and non-typhoid fever, gastroenteritis, urethritis, otitis media, septicemia, osteomyelitis and any other infections caused by these pathogenic bacterial strains. Aqueous extracts could not inhibit any of the isolates used, whereas ethanol extracts of stem-D inhibited MRSA (40), E. coli (27), E. faecium (24), S. flexneri (12) and S. typhimurium (R); leaf-E all tested organisms (2339) and root-F MRSA (26), E. coli (33), S. mutans (15), S. typhimurium (R), S. flexneri (R) and E. faecium (R) millimetre zones of inhibitions. However, ethyl acetate extracts of stem-G inhibited E. coli (22), S. typhimurium (32), E. faecium (19), others resistance (R); Leaf-H all isolates (14-31) and root-I MRSA (23), E. coli (24), E. faecium (20), S. mutans (15), others resistance (R). Streptomycin-J inhibited all except $S$. mutans between 10 27 millimetre diameters. Results showed that the leaf extract of $M$. longistyla was more potent than extracts of other parts of the plant. Hence, M. longistyla leaf contains more active ingredients than the stem and root (Table 1). The inability of aqueous extracts to inhibit the growth of the bacterial strains may be due to its low extraction ability. The findings agreed with Ogah and Osundare's (2015) report, which observed that aqueous extract showed little or no activity against tested strains, suggesting that water may have a low penetration and extraction ability compared to organic solvents. Other researchers had also supported this view that organic solvent extracts exhibited higher antibacterial activity than aqueous extracts. The antibacterial principles may be either polar or non-polar since extraction can be with organic solvents or aqueous media (Britto, 2001). Odeleye et al. (2016) reported that aqueous extracts' poor inhibition ability might be due to the weak solubility nature of the plants' active components in water.

Minimum inhibitory concentration (MIC) of the plant extracts (Table 4) showed the following range against MRSA (25-50), E. coli (25-100), S. typhimurium (25-50), S. flexneri (25-100) and S. mutans (25-100) milligram per millimetre. The MICs implied that the extracts had some substantial effects on the test organisms. $\square$

The result of the GC-MS analysis revealed certain bioactive compounds such as fatty acids, amino acids, vitamin $\mathrm{E}$, and their derivatives, which were shown to have medicinal properties. It showed that isophorone is prevalent in the three parts of the plant studied; it is the most prevalent in the MLL and MLR, and the second most prevalent in MLS (Table 5). Besides, the isophorone, which is common to the three parts, the leaf (MLL) has 1methoxymethoxy-oct-2-yne, 7-chloro-3-heptyne, 11dodecyn-1-ol acetate as prominent components. The root (MLR) also presented linoleic acid ethyl ester, 3-eicosene, octadecanoic, n-hexadecanoic acid, and their ester derivatives as prominent components. The stem (MLS), however, has $5 \mathrm{H}, 6 \mathrm{H}, 7 \mathrm{H}$-cyclopenta[d]pyrimidin-2-amine as the most prominent compound alongside hexadecanoic ethyl ester, Vitamin E and Squalene. Other bioactive components identified include 3-ethyl-1-pyrroline and morpholines. 
Table 5. Bioactive Compounds identified in the Macrosphyra longistyla ethanol extract of the leaf (MLL), root (MLR) and stem (MLS) and their characteristics

\begin{tabular}{|c|c|c|c|c|c|}
\hline $\begin{array}{c}\text { Peak } \\
\quad \#\end{array}$ & $\begin{array}{c}\mathrm{RT} \\
\text { (Min) }\end{array}$ & Compound name & $\begin{array}{l}\text { Molecular } \\
\text { formulae }\end{array}$ & $\begin{array}{l}\text { Molecular Weight } \\
\left(\mathrm{gmol}^{-1}\right)\end{array}$ & $\%$ Peak Area \\
\hline \multicolumn{6}{|l|}{ MLL } \\
\hline 1 & 4.191 & Aziridine, 1-(2-buten-1-yl)-, (Z)- & $\mathrm{C}_{6} \mathrm{H}_{11} \mathrm{~N}$ & 97.16 & 2.76 \\
\hline 2 & 4.775 & 3-Methyl-3-hexene & $\mathrm{C}_{7} \mathrm{H}_{14}$ & 98.19 & 3.16 \\
\hline 3 & 5.204 & Propanenitrile, 3-amino-2,3-dihydroxymino)- & $\mathrm{C}_{3} \mathrm{H}_{4} \mathrm{~N}_{4} \mathrm{O}_{2}$ & 128.09 & 2.32 \\
\hline 4 & 8.351 & Isophorone* & $\mathrm{C}_{9} \mathrm{H}_{14} \mathrm{O}$ & 138.21 & 33.54 \\
\hline 5 & 13.043 & 4-Cyclopentene-1,3-diol, trans- & $\mathrm{C}_{5} \mathrm{H}_{8} \mathrm{O}_{2}$ & 100.12 & 1.06 \\
\hline 6 & 13.861 & 2-Azatricyclo[4.3.1.1(4,8)]undecane & $\mathrm{C}_{10} \mathrm{H}_{17} \mathrm{~N}$ & 151.25 & 1.20 \\
\hline 7 & 14.805 & Benzaldehyde, 2-nitroso- & $\mathrm{C}_{7} \mathrm{H}_{5} \mathrm{NO}_{2}$ & 135.12 & 1.58 \\
\hline 8 & 15.486 & Octadecane, 1-(ethenyloxy)- & $\mathrm{C}_{20} \mathrm{H}_{40} \mathrm{O}$ & 296.50 & 1.21 \\
\hline 9 & 16.127 & Oxirane, 2,2'-(1,4-butanediyl)bis- & $\mathrm{C}_{8} \mathrm{H}_{14} \mathrm{O}_{2}$ & 142.20 & 1.15 \\
\hline 10 & 17.684 & 2-Hexyn-1-ol & $\mathrm{C}_{6} \mathrm{H}_{10} \mathrm{O}$ & 98.14 & 1.46 \\
\hline 11 & 18.313 & 3-Heptyne, 7-chloro- & $\mathrm{C}_{7} \mathrm{H}_{11} \mathrm{CL}$ & 130.61 & 9.10 \\
\hline 12 & 21.672 & Paromomycin & $\mathrm{C}_{23} \mathrm{H}_{45} \mathrm{~N}_{5} \mathrm{O}_{14}$ & 615.60 & 1.45 \\
\hline 13 & 22.427 & 1-Pyrroline, 3-ethyl- & $\mathrm{C}_{16} \mathrm{H}_{15} \mathrm{~N}$ & 97.16 & 1.56 \\
\hline 14 & 22.707 & 7-Oxabicyclo[4.1.0]heptane, 1,5-dimethyl- $\square$ & $\mathrm{C}_{8} \mathrm{H}_{14} \mathrm{O}$ & 126.20 & 2.48 \\
\hline 15 & 22.851 & 11-(2-Cyclopenten-1-yl)undecanoic acid, (+)- & $\mathrm{C}_{16} \mathrm{H}_{28} \mathrm{O}$ & 252.39 & 1.41 \\
\hline 16 & 23.451 & 1-Methoxymethoxy-oct-2-yne** & $\mathrm{C}_{10} \mathrm{H}_{18} \mathrm{O}_{2}$ & 170.25 & 27.02 \\
\hline 17 & 23.583 & 11-Dodecyn-1-ol acetate & $\mathrm{C}_{14} \mathrm{H}_{24} \mathrm{O}_{2}$ & 224.34 & 3.85 \\
\hline 18 & 25.105 & 4-Acetoxy-3-methylbut-2-enoic acid, methyl ester $\square$ & $\mathrm{C}_{8} \mathrm{H}_{12} \mathrm{O}_{4}$ & 172.18 & 1.07 \\
\hline 19 & 25.397 & 8-Nonynoic acid & $\mathrm{C}_{9} \mathrm{H}_{14} \mathrm{O}_{2}$ & 154.21 & 1.08 \\
\hline 20 & 26.318 & Trichloroacetic acid, 2-methyloct- 5-yn-4-yl ester & $\mathrm{C}_{11} \mathrm{H}_{15} \mathrm{Cl}_{3} \mathrm{O}_{2}$ & 285.60 & 1.54 \\
\hline \multicolumn{6}{|l|}{ MLR } \\
\hline 1 & 4.730 & 2(5H)-Furanone, 5-methyl- & $\mathrm{C} 5 \mathrm{H} 6 \mathrm{O} 2$ & 98.10 & 2.49 \\
\hline 2 & 5.001 & Morpholine & C4H9NO & 87.12 & 4.05 \\
\hline 3 & 8.268 & Isophorone* & $\mathrm{C} 9 \mathrm{H} 14 \mathrm{O}$ & 138.21 & 30.35 \\
\hline 4 & 18.75 & (5-Carbamoyl-2,4-dioxo-3H-pyrimidin-1-yl) acetic acid & C7H7N3O5 & 213.15 & 0.40 \\
\hline 5 & 19.562 & Pentadecanoic acid, 14-methyl & C16H32O2 & 256.42 & 2.29 \\
\hline 6 & 20.493 & n-Hexadecanoic acid & C16H32O2 & 256.42 & 10.24 \\
\hline 7 & 20.629 & Octadecanoic acid & C18H36O2 & 284.48 & 10.90 \\
\hline 8 & 23.452 & Linoleic acid ethyl ester $* *$ & С20H36O2 & 308.50 & 17.12 \\
\hline 9 & 23.522 & 3-Eicosene, (E)- & $\mathrm{C} 2 \mathrm{OH} 40$ & 280.53 & 15.15 \\
\hline 10 & 23.918 & Octadecanoic acid, ethyl ester & C20H40O2 & 312.53 & 3.729 \\
\hline 11 & 28.651 & Benzene, 1-isothiocyanato-2-methyl & C8H7NS & 149.21 & 1.02 \\
\hline 12 & 30.856 & 2-Buten-1-ol, (E)-, TBDMS derivative & C10H22OSi & 186.37 & 0.21 \\
\hline 13 & 31.056 & 2,6,10-Dodecatrien-1-ol, 3,7,11-trimethyl & $\mathrm{C} 15 \mathrm{H} 260$ & 222.37 & 2.05 \\
\hline \multicolumn{6}{|l|}{ MLS } \\
\hline 1 & 5.078 & Propanoic acid, 2-methylpropyl ester & $\mathrm{C}_{7} \mathrm{H}_{14} \mathrm{O}_{2}$ & 130.18 & 1.26 \\
\hline 2 & 8.271 & Isophorone $e^{* *}$ & $\mathrm{C}_{9} \mathrm{H}_{14} \mathrm{O}$ & 138.21 & 18.37 \\
\hline 3 & 18.118 & Cyclohexanone, 2,2-dimethyl-5-(ethyloxiranyl) & $\mathrm{C}_{12} \mathrm{H}_{20} \mathrm{O}_{2}$ & 196.29 & 1.24 \\
\hline 4 & 18.49 & 5H,6H,7H-Cyclopenta[d]pyrimidin-2-amine* & $\mathrm{C}_{7} \mathrm{H}_{9} \mathrm{~N} 3$ & 135.17 & 30.93 \\
\hline 5 & 20.625 & Hexadecanoic acid, ethyl ester & $\mathrm{C}_{18} \mathrm{H}_{36} \mathrm{O}_{2}$ & 284.48 & 16.46 \\
\hline 6 & 23.451 & Linoleic acid ethyl ester & $\mathrm{C}_{20} \mathrm{H}_{36} \mathrm{O}_{2}$ & 308.50 & 12.64 \\
\hline 7 & 31.044 & Squalene & $\mathrm{C}_{30} \mathrm{H}_{50}$ & 410.72 & 4.90 \\
\hline 8 & 33.585 & Vitamin E & $\mathrm{C}_{29} \mathrm{H}_{50} \mathrm{O}_{2}$ & 430.71 & 14.20 \\
\hline
\end{tabular}

* most prevalent phytochemical in each plant's part

** the second most prevalent

Isophorone, the phytochemical, which is common to the three parts, is a well-known plant metabolite that has been used as an industrial solvent. It is used as a carrier of pesticide for plants, and when partly hydrogenated, it forms a derivative, trimethylcyclohexanone, a common raw material for polycarbonates production. Polycarbonate can further be reacted with phenol to give an analogue of bisphenol A with potent antimicrobial properties; the antimicrobial is usually used to disinfect skin or wound.
The high level of this solvent may suggest exogenous sources from pesticide applications.

The long-chain fatty acids, which are the major components of the root extracts, linoleic acid ethyl ester and octadecanoic acid, are well known for their nutritional values. Besides, octadecanoate is a potent antifungal and antibacterial compound; the antioxidant, hypocholesterolemic, and nematicide, activities of nhexadecanoic acid is also well known (Elaiyaraja and 
Chandramohan, 2018). The stem, however, has 5H,6H,7Hcyclopenta[d]pyrimidin-2-amine as its prominent compound; pyrimidin-2-amine is presently being considered as an anticancer drugs and H3 receptor antagonist (Tadesse et al. 2018; Wagner et al. 2019). H3 receptor antagonists are principal in allergy prevention and autoimmune response suppression. The presence of vitamin $\mathrm{E}$ and squalene in stem bark collaborated the presence of flavonoid in the previous analysis, so did the lowest DPPH scavenging IC50 recorded by MLS extract in that study. Squalene has a role in topical skin lubrication and protection against pathogens (Pappas, 2009); in addition to the aforementioned, vitamin $\mathrm{E}$ has been reported to demonstrate antioxidant, anti-aging and antiinflammatory activities (Saliha et al., 2014). It was also observed that the plant extracts had particular alkyne groups such as 1-methoxymethoxy-oct-2-yne, 7-chloro-3heptyne, and 11-dodecyn-1-ol acetate and some bioactive ring structure (Figure 4). These alkyne groups are known with rare bioactivities such as antiprotozoal and nematocidal activities (Jorgensen et al., 1996 ).
The presence of a 3-ethyl-1-pyrroline suggests that the compound could be responsible for the scent (aroma) of the plant leaf. A similar compound, 2-acetyl-1-pyrroline, has been implicated in aromatic rice and other plants (Routray and Rayaguru, 2018). Also, propanenitrile, 3amino-2,3-di (hydroxymino)- has been reported in the volatile compounds identified from root exudates of chilli seedling primed with 6\% Bacillus amyloliquefaciens (Sathya et al. 2016). Morpholines are widely used in organic synthesis. They serve as -building blocks in the preparation of the antibiotic linezolid, the anticancer agent gefitinib (Iressa), and the analgesic dextromoramide (Wikipedia, 2019). Recently, some studies have shown that morpholines derivative, 1-[4-(morpholin-4-yl) phenyl]-5-phenylpenta-2,4- dien-1- one, is a potent monoamine oxidase inhibitor (Maliyakkal et al. 2020). Monoamine oxidase inhibitors are effective antidepressant drugs that have found usage in social phobia and panic disorder.

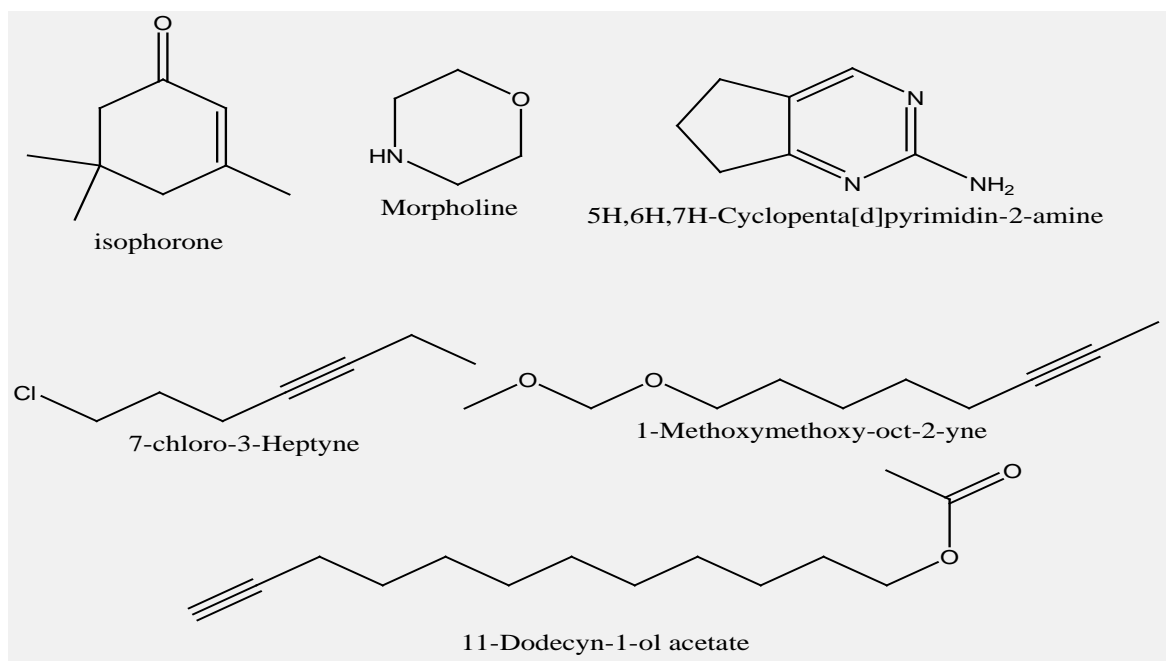

Figure 4. Prominent bioactive compounds and rare alkyne groups identified from the GCMS analysis of Macrosphyra longistyla extracts

\section{Conclusion}

The presence of arrays of phytochemicals or bioactive ingredients such as alkaloids, saponins, tannins, flavonoids, phlobatanins, isophorone, squalene, morpholine, vitamin $\mathrm{E}$ and host of others revealed in this study, which were implicated in the treatment of certain ailments, has provided a scientific justification for the use of Macrophyla longistyla as an alternative remedy for the treatment of bacterial infections, hence acting as a potential source of drugs with broad-spectrum activity. Furthermore, the GCMS identified plants alkynes, and pyrimidin-2-amine suggested the possible anticancer and antihistamine potentials of the plant. These, however, need to be verified through further studies. In the meantime, studies are also ongoing on the toxicity, pharmacological evaluation, and structural elucidation of the plant's active principles since this will enhance the plant materials' potency at lower concentrations.

\section{References}

Agyare C, Owusu-Ansah A, Ossei PPS, Apenteng JA and Boakye YD. 2014. Wound Healing and Anti-Infective Properties of Myrianthus arboreus and Alchornea cordifolia. Medicinal Chemistry, 4:533-539.

Al-Jadidi HSK, and Hossain AM. 2016. Determination of the total phenols, flavonoids, and antimicrobial activity of the crude extracts from locally grown neem stems. Asian Pacific Journal of Tropical Disease, 6: 376-379.

Amarowicza R, Peggb RB, Rahimi-Moghaddamc P, Barld B and Weilc JA. 2004. Free-radical scavenging capacity and antioxidant activity of selected plant species from the Canadian prairies. Food Chem, 84: 551-562.

Andersson DI and Levin BR. 1999. The biological cost of antibiotic resistance, Curr. Opin. Microb. 2:489-493.

Arbonnier M. 2000. Arbres, arbustes et lianes des zones sèches d'Afrique de l'Ouest. CIRAD, MNHN, UICN. 541 pp.

Atolani O, Adeyemi SO, Akpan E, Adeosun CB and Olatunji GA. 2011. Chemical Composition and Antioxidant Potentials of Kigelia pinnata Root Oil and Extracts Excli Jour, 10: 264-273. 
Bejina F, Bystricky M and Ingrin J. 2011. Experimental Deformation of Polyphase Aggregates at Pressures and Temperatures of the Upper Mantle. American Geophysical Union, Fall Meeting 2011, abstract id. MR11B-2173.

Belakhdar G, Benjouad A, Abdennebi EH.2015. Determination of some bioactive chemical constituents from Thesium humile Vahl. J Mater Environ Sci, 6: 2778-83.

Bouyahya A, Abrini J, El-Baabou A, Bakri Y, and Dakka N.2016. Determination of phenol content and antibacterial activity of five medicinal plants ethanolic extracts from north-west of Morocco. J Plant Pathol Microbiol, 7: 107-111.

Britto JS. 2001. Comparative Antibacterial Activity Study of Solanum incanum Lam. Jour Swamy Bot Club, 18:81-82.

Burkill HM. 1995. The useful plants to West tropical Africa, Ed 2, vol.3, Royal Botanic Gardens. Kew. 274pp.

Cheesbrough M. 2004. Microscope. In: District Laboratory Practice in Tropical Countries. Part 1, Low price Egyptian edition 2013. The Anglo-Egyptian Bookshop \& Cambridge University Press, pp: 110.

Davies J and Davies D. 2010. Origins and evolution of antibiotic resistance, Microbiology, and Molecular. Biology Reviews, 74: 417-433.

Ebrahimzadeh MA, Pourmorad F and Hafezi S. 2008. Antioxidant activities of Iranian corn silk. Turkish Journal of Biology, 32:4349.

Elaiyaraja A, Chandramohan G, 2018. Comparative Phytochemical Profile of Crinum Defixum Ker-Gawler Leaves Using GC-MS, Journal of Drug Delivery and Therapeutics, 8(4): 365-380

Elufioye TO, Chinaka CG and Oyedeji AO. 2019. Antioxidant and Anticholinesterase Activities of Macrosphyra Longistyla (DC) Hiern Relevant in the Management of Alzheimer's Disease. Antioxidants, 8 (9), 400. doi:10.3390/antiox8090400

Govaerts B, Schum FT, Benith A and Hook F. 2003. Word checklist of selected Plant Families Database in Access. The Board of Trustees of the Royal Botanic Gardens Kew (http://powo.science.kew.org/taxon/urn:lsid:ipni.org:names:34870 -1\#source-FTEA), Accessed on the $5^{\text {th }}$ of May, 2019.Harborne JB. 1998. Phytochemical Methods A Guide to Modern Techniques of Plant Analysis, London: Springer. 64 pp.

Jaiswal J and Sharma B. 2020. A Comparative Study of Antimicrobial and Pharmacological Properties of Argemone mexicana, Solanum xanthocarpum and Thevetia peruviana. Acta Scientific Microbiology, 3(3):1-5. Doi: 10.31080/ ASMI. 2020.03.0524

Jorgensen, T., Montresor, A., and Savioli, L., 1996. Effectively controlling strongyloidiasis. Parasitol. Today, 12:164.

Karou SD, Tchacando T, Ilboudo DP and Simpore J. 2011. SubSaharan Rubiaceae: A Review of Their Traditional Uses, Phytochemistry, and Biological Activities. Pakistan Journal of Biological Sciences, 14(3): 149-169.

Karthikeyan A, Shanti V and Nagasathaya A. (2009). Preliminary phytochemical and antibacterial screening of crude extracts of the leaf of Adhatoda vasica L. International Journal of Green Pharmacy, (3):78-80.

Kudumela RG and Masoko P. 2018. In Vitro Assessment of Selected Medicinal Plants Used by the Bapedi Community in South Africa for Treatment of Bacterial Infections. Journal of Evidence-based Integrative Medicine, 23:1-10

Kunitz M. 1947. Journal of General Physiology, 30: 291.

Larrauri JA, Sanchez-Moreno C, Rupérez P and Saura-Calixto F. 1999. Free Radical Scavenging Capacity in the Aging of Selected
Red Spanish Wines. Journal of Agricultural and Food Chemistry, 47(4):1603-1606.

Lopez-Rubalava C and Estrada-Camarena E. 2016. Mexican medicinal plants with anxiolytic or antidepressant activity: focus on preclinical research. J Ethnopharmacol,186: 377-391.

Maffo T, Wafo P, Teoua Kamdem RS, Melong R, Uzor PF, Mkounga P, Ali, Z and Ngadjui, BT 2015. Terpenoids from the stem bark of Neoboutonia macrocalyx (Euphorbiaceae). Phytochem Lett, 12: 328-331.

Mak, Y.W., Chuah, L.O., Ahmad, R., Bhat, R., 2013. Antioxidant and antibacterial activities of hibiscus (H. rosa-sinensis L.) and Cassia (Senna bicapsularis L.) flower extracts. Journal of King Saud University- Science, 25:275-282.

Maliyakkal N, Eom BH, Heo JH, Almoyad MAA, Parambi DGT, Gambacorta N, Nicolotti O, Beeran AA, Kim H, Mathew B. 2020. A New Potent and Selective Monoamine Oxidase-B Inhibitor with Extended Conjugation in a Chalcone Framework: 1-[4-(Morpholin-4-yl)phenyl] -5-phenylpenta-2,4- dien-1-one, ChemMedChem, 10.1002/cmdc.202000305, 0, 0.

Ochei J and Kolhatkar A. 2004. Medical Laboratory Science; Theory and Practice. McGraw-Hill Publishing Company Limited, New Delhi.

Odeleye OF, Okunye OL, Kesi C and Abatan TO. 2016. Study of the Anticaries Activity of Three Common Chewing Sticks and Two Brands of Toothpaste in South West Nigeria” British Journal of Pharmacological Research, 11(5): 1-7. Article no. BJPR 26004.

Odugbemi T. (2008). (Ed) A Textbook Medicinal Plant from Nigeria. University of Lagos press. Lagos, Nigeria. 628 pp.

Odumosu TB, Olanike MB, Okeke CJ, Ogah JO and Michel FC. Jr 2017. Antimicrobial activities of the Streptomyces coelicolor strain AOB KF977550 isolated from a tropical estuary. Journal of Taibah University for Science, 11: 836-841.

Ogah JO and Osundare FA. 2015. Evaluation of Antibacterial Activity and Preliminary Phytochemical Screening of Moringa oleifera on Pathogenic Bacteria. International Journal of Pharmacology Research, 5(11): 310-315.

Pappas A. 2009. "Epidermal surface lipids". Dermatoendocrinology. 1(2): 72-76. doi:10.4161/derm.1.2.7811. PMC 2835894. PMID 20224687.

Parekh J and Chanda S. 2007. Antibacterial and phytochemical studies on twelve species of Indian medicinal plants. African Journal of Biomedical Research, 10: 175 - 181.

Routray W and Rayaguru K. 2018. 2-Acetyl-1-pyrroline: A key aroma component of aromatic rice and other food products, Food Reviews International, 34:6, 539-565,

Sacan O. 2018. Antioxidant Activity, Total Phenol and Total Flavonoid Contents of Trachystemon orientalis (L.) G. Don. European Journal of Biology, 77(2): 70-75.

Saliha R, Syed T, Faizal A, Absar A, Shania A and Farzana M, 2014. The Role of Vitamin E in Human Health and Some Diseases. Qaboos Univ Med J. 14(2): e157-e165.

Sanchez-Moreno C, Larrauri JA and Saura-Calixto F. 1998. A procedure to measure the antiradical efficiency of polyphenols. Journal of the Science of Food and Agriculture, 76: 270-276.

Sathya S Lakshmi, S., and Nakkeeran S. 2016. Combined effect of biopriming and polymer coating against chilli damping off. International Journal of Agricultural Science and Research,6(3): 45-54.

Saranraj P and Sivasakthi S. 2014. Medicinal plants and its antimicrobial properties: A review. Global Journal of pharmacology, 8(3):316-327. 
Sasidharan S, Chen Y, Saravanan D, Sundram KM and Yoga Latha L. 2011. Extraction, Isolation, and Characterization of Bioactive Compounds from Plants' Extracts. African Journal Traditional, Complementary Alternative Medicine, 8(1): 1-10.

Schubert A, Pereira DF, Zanin FF, Alves SH, Beck RCR and Athayde ML. 2007. Comparison of antioxidant activities and tota polyphenolic and methylxanthine contents between the unripe fruit and leaves of Ilex paraguariensis A. St. Hil. Pharmazie, 62: 876-880.

Singh R. and Sharma B. 2019.'Therapeutic Potential of PlantBased Natural Compounds for Malaria-Recent Advances and Future Perspectives”. EC Pharmacology and Toxicology, 7(10):1078-1089.

Singh N, Jaiswal J, Tiwari P and Sharma B. 2020. Phytochemicals from Citrus Limon Juice as Potential Antibacterial Agents. The Open Bioactive Compounds Journal, 8:1-6.

Singleton, V.L. and Rossi, J.A.1965. Colorimetry of Total Phenolics with Phosphomolybdic-Phosphotungstic Acid Reagents. American Journal of Enology and Viticulture, 16:144-158.

Tadesse S, Yu M, Mekonnen LB, Lam F, Islam S, Tomusange K, Rahaman MH, Noll B, Basnet SKC, Teo T, Albrecht H, Milne R and Wang S. 2017. Highly Potent, Selective, and Orally Bioavailable 4-Thiazol-N-(pyridin-2-yl) pyrimidin-2-amine Cyclin-Dependent Kinases 4 and 6 Inhibitors as Anticancer Drug Candidates: Design, Synthesis, and Evaluation Journal of Medicinal Chemistry, 60 (5), 1892-1915
Trease GE and Evans WC. 2002. Pharmacognosy, Univ. Press, Aberdeen, Great Britain. Pp 161-163.

Wang H, Khor TO, Shu L, Su Z, Fuentes F, Lee, J and Kong AT. 2012. Plants Against Cancer: A Review on Natural Phytochemicals in Preventing and Treating Cancers and Their Druggability”. Anticancer Agents in Medicinal Chemistry, 12 (10): 1281-1305.

Wágner G, Mocking T, Arimont M, Provensi G, Rani B, SilvaMarques B, and Leurs R. 2019. 4-(3-Aminoazetidin-1-yl) pyrimidin-2-amines as high-affinity non-imidazole histamine H3 receptor agonists within vivo central nervous system. Journal of Medicinal Chemistry, 62(23), 10848-10866.

Yigit D. 2018. Antimicrobial and Antioxidant Evaluation of Fruit Extract from Cornus mas L. Aksaray University Journal of Science and Engineering, 2(1): 41-51.

Zadra M, Piana M, Faccim de Brum T, Boligon AA, Borba de Freitas R, Machado MM, Stefanello ST, Soares FAA and Athayde ML. 2012. Antioxidant Activity and Phytochemical Composition of the Leaves of Solanum guaraniticum A. St.-Hil. Molecules, 17: 12560-12574. 